\title{
Ovulatory Pain
}

National Cancer Institute

\section{Source}

National Cancer Institute. Ovulatory Pain. NCI Thesaurus. Code C78514.

Painful sensation in one side of the abdomen between menstrual cycles, around the time of the discharge of the ovum from the ovarian follicle. 